\title{
Qualitative Evaluation
}

National Cancer Institute

\section{Source}

National Cancer Institute. Qualitative Evaluation. NCI Thesaurus. Code C49143.

A type of evaluation that is primarily descriptive and interpretative, and may or may not lend itself to quantification. Mainly concerned with the properties, the state, and the character (i.e., the nature) of phenomena. It implies an emphasis on processes and meanings that are rigorously examined, but not measured in terms of quantity, amount, or frequency. (www.unfpa.org/monitoring/toolkit/glossary.pdf and Nonprofit Good Practice Guide Glossary) 